\title{
The Effect of Group Counseling Based on Cognitive-behavioral Approach on Self-Care Behaviors and Illness Perception of Middle-aged Women with Diabetes Type 2: A Quasi-experimental Study

\author{
Marysm Dafei' ${ }^{1}$ Sedighe Hatefi*2, Ali Dehghani
}

1. Assistant Professor, Research Center for Nursing and Midwifery Care, Faculty of Nursing \& Midwifery, Shahid Sadoughi University of Medical Sciences, Yazd, Iran

2. Msc counseling in Midwifery, Department of Midwifery, International Campus University, Shahid Sadoughi University of Medical Sciences, Yazd, Iran

3. Associated Professor, Department of Statistics, School of Shahid Sadoughi University of Medical Sciences, Yazd, Iran Health, Shahid Sadoughi University of Medical Sciences, Yazd, Iran

\section{Article Info}

Received: 2020/01/23;

Accepted: 2020/04/29;

Published Online: 2020/08/22

10.30699/ajnmc.28.3.216

Original Article

Use your device to scan and read the article online

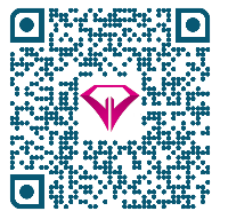

\section{ABSTRACT}

Introduction: Illness Perception and self-care behaviors are essential elements in treatment and management of patients with diabetes. The aim of this study was to investigate the effect of group counseling with a cognitive-behavioral approach to illness perceived and self-care behaviors in middle-aged women with type 2 diabetes (T2D).

Methods: The present study is a quasi - experimental study with two groups of intervention and control in parallel with pre-test, post-test and one-month control in Isfahan, Iran, comprehensive health centers. For each group, 32 middle-aged women with T2D were selected by convenience sampling. Both groups received routine care of diabetic patients, but the experimental group received a cognitive behavioral group-counseling program. Data was collected through demographic questionnaire, the illness perception questionnair (IPQ), and summary of diabetes self-care activity (SDCS) and a checklist. Data was analyzed by SPSS 16 software using descriptive statistics, Chi-square test and independent t-test with P-values are less than 0.05.

Results: The groups were not significantly different demographically. The mean age was $38.65 \pm 4.23$ and $39.19 \pm 4.87$, and the duration of diagnosis was 2 years and less. Of patients, $77 \%$ had a history of hypertension or hyperlipidemia or both in both groups. There were no significant differences in self-care behaviors $(\mathrm{t}=-0.0222, P=0.859)$ and illness perception $(\mathrm{t}=-0.178, P=0.859)$ in the pre-test. However, in the post-test, the intervention group showed a significant improvement in self-care behaviors $(\mathrm{t}=4.25$, $P=0.01)$ and disease perception $(\mathrm{t}=3.93$, standard deviation $=0.87)$. There was also an improvement in self-care behaviors $(\mathrm{t}=4.41$ and $P=0.014)$ and illness perception $(\mathrm{t}=414$ and $P=0.01)$ in the follow-up period, indicating the persistence of changes in counseling

Conclusion: Group counseling based on cognitive-behavioral approach can enhance the perception of disease and self-care behaviors in T2D. Therefore, it can be used as a therapeutic approach to medication for patients with T2DM.

Keywords: Cognitive behavioral approach, Type 2 diabetes, Group counseling, Disease perception, Self-care behaviors, Iran
1. Sedighe Hatefi, Msc counseling in Midwifery, Department of Midwifery, International Campus University, Shahid Sadoughi University of Medical Sciences, Yazd, Iran

Copyright $(2020$, This is an original open-access article distributed under the terms of the Creative Commons Attribution-noncommercial 4.0 International License which permits copy and redistribution of the material just in noncommercial usages with proper citation.

How to Cite This Article:

Dafei M, Hatefi S, Dehghani A. The Effect of Group Counseling Based on Cognitive-behavioral Approach on Self-Care Behaviors and Illness Perception of Middle-aged Women with Diabetes Type 2: A Quasi-experimental Study. Avicenna J Nurs Midwifery care. 2020; 28 (3) :216-226 
بررسى تأثير مشاورة گروهى مبتنى بر رويكرد شناختى -رفتارى بر رفتارهاى خودمراقبتى و ادراك از بيمارى در زنان ميانسال مبتلا به ديابت نوع ب: يك مطالعة نيمه تجربى

\title{
مريم دافعى'، صديقه هاتفى ب**، على دهقانى
}

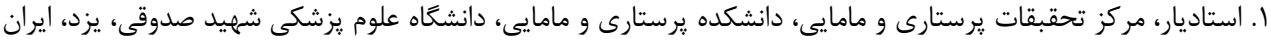

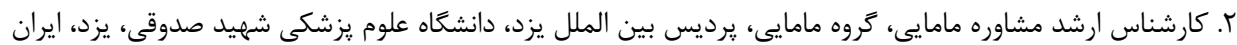

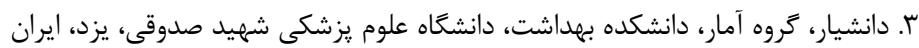

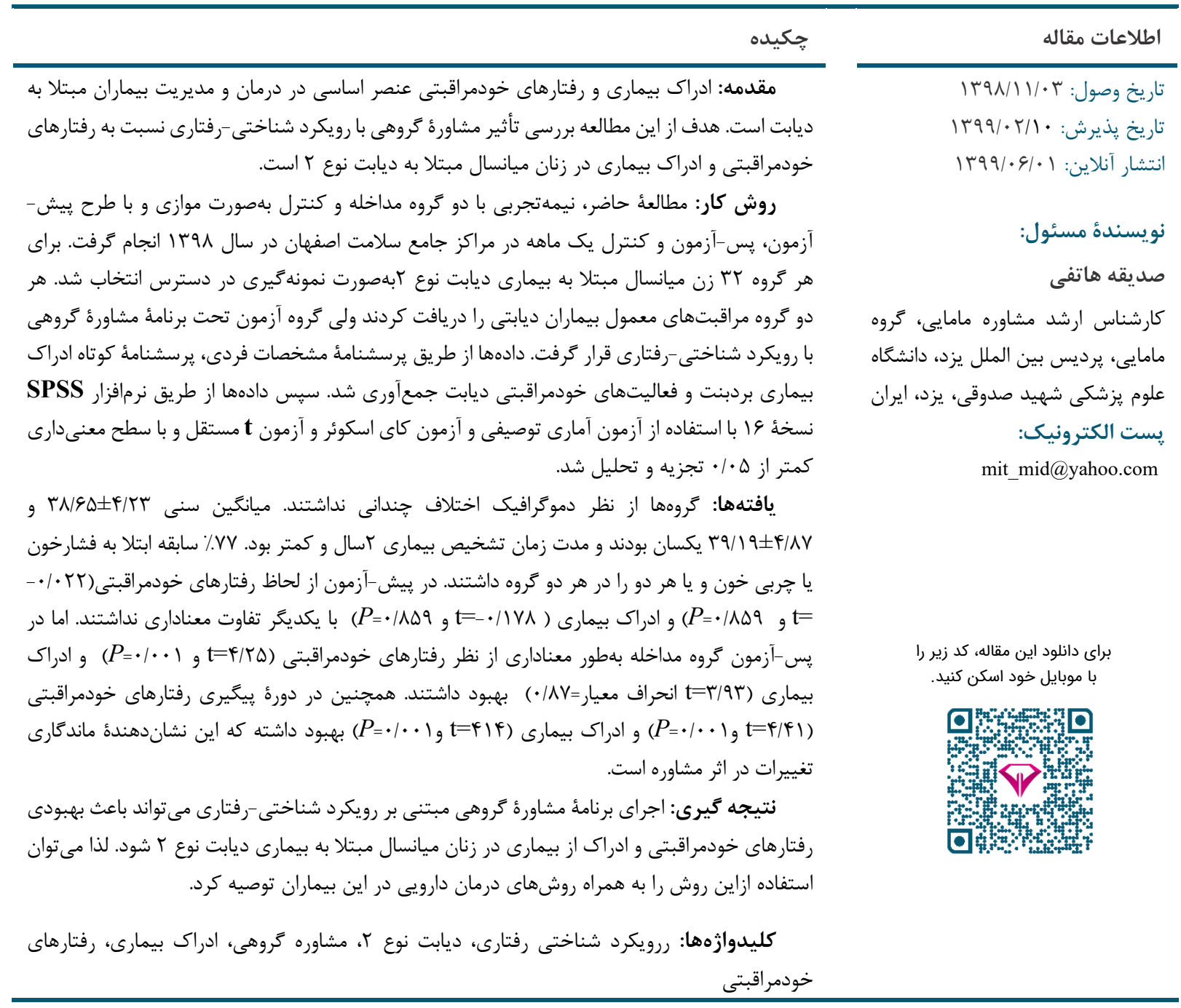

از شايعترين و يرهزينهترين بيمارىهاى مزمنى است كه

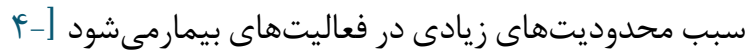

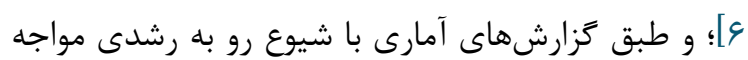

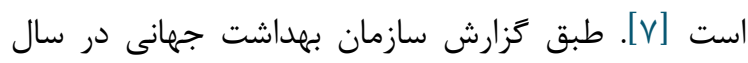

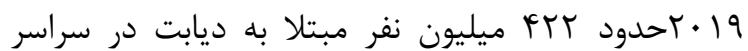

از بزرگترين ُالشهاى قرن بيست و يكمم كه

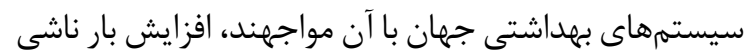

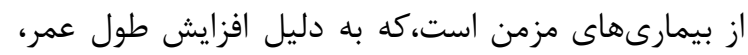

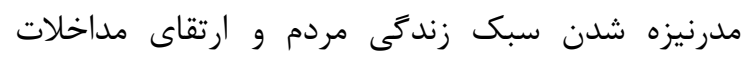

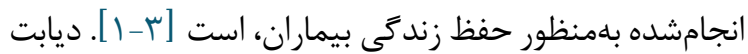


سطح مراكز مختلف مواجه هستيم استفاده از شيوههاى

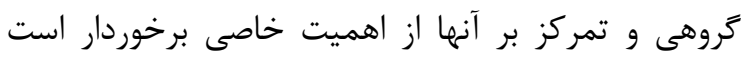

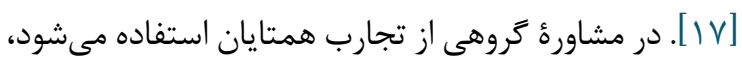

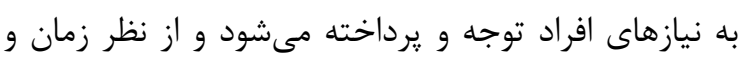

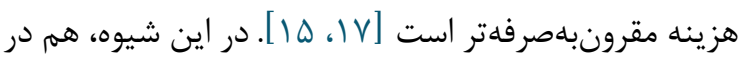
فرايندهاى شناختى و هم در رفتارهاى مددجوتغيير ايجاد مى شود [r [r

با توجه به افزايش تعداد بيماران ديابتى و اهميت

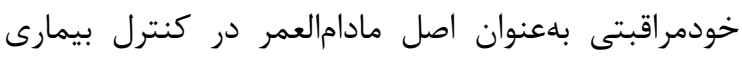

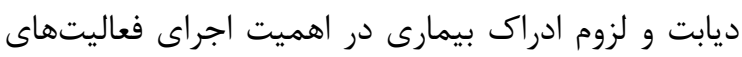

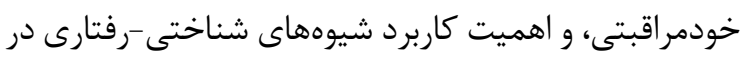

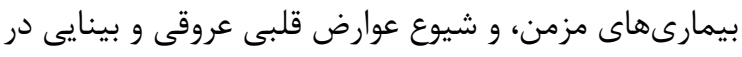

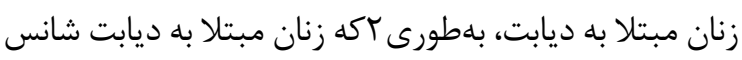

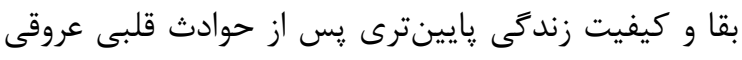

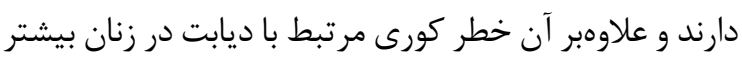

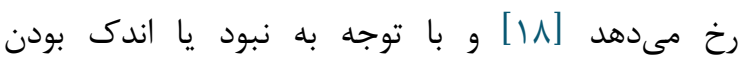

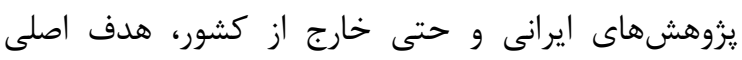

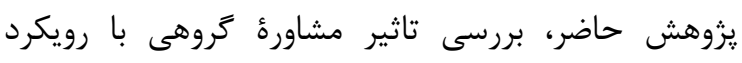

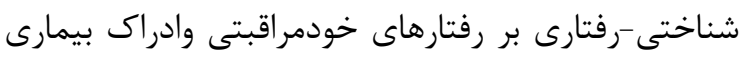

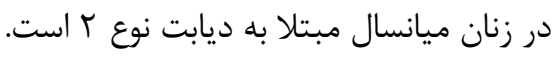

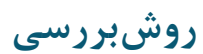

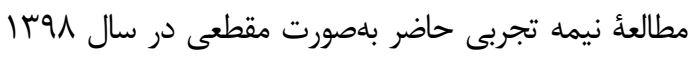

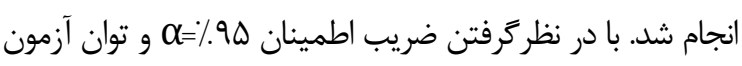
.

$$
\mathrm{n}=\frac{2 \mathrm{~s}^{2} \mathrm{p}\left[\mathrm{z}_{1-\alpha / 2}+\mathrm{z}_{1-\beta}\right]^{2}}{\mu^{2} \mathrm{~d}}
$$

حجم نمونهٔ اوليه جץ نفر در هر كروه برآورد شد كه با احتساب

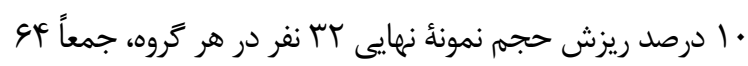

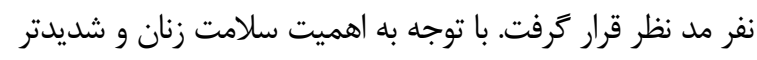
بودن عوارض در زنان و احتمال سوكيرى در استفاده از دو نفر مشاور

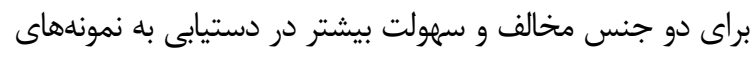

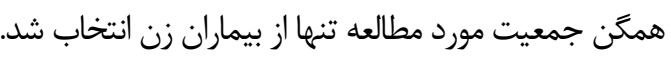

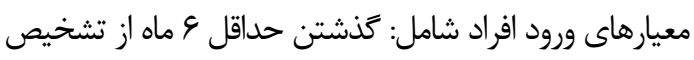

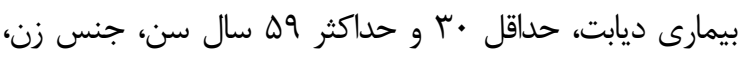

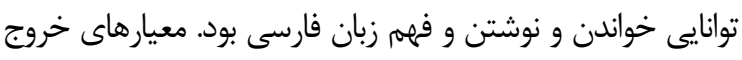

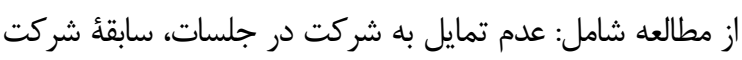

${ }^{2} \mathrm{CBT}$
جهان شناخته شده كه بيشتر آنان در كشورهاى كمدر آمد و

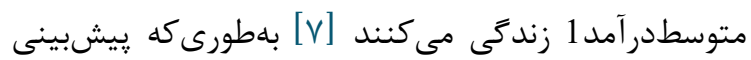

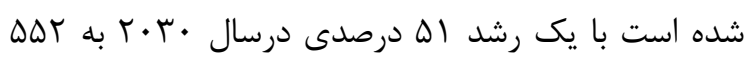
ميليون نفر در جهان خواهد رسيد [11-11]. براى كنترل بيمارى ديابت علاوهبر مصرف منظهم

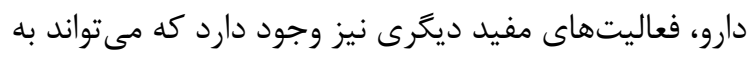
بهبود كيفيت زندگى بيماران ديابتى كمك كند. يعنى دئى كنترل

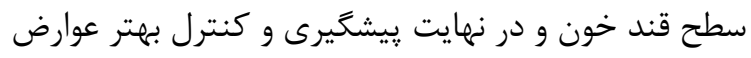

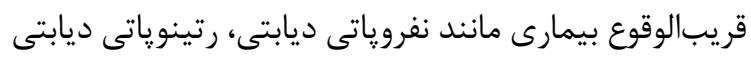

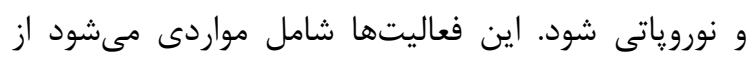

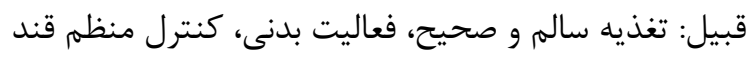

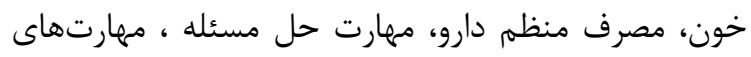

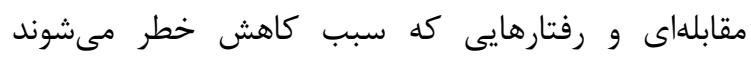

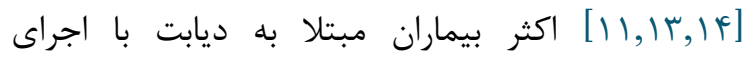

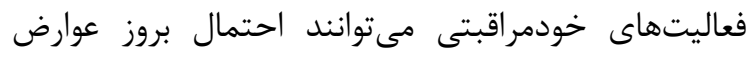

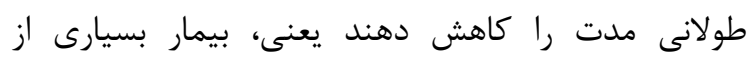

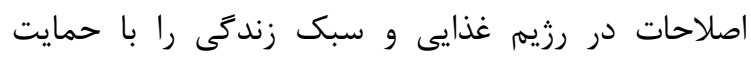
مراقبين بهداشتى از طريق كسب اطلاعات و ارتقاى اعتماد

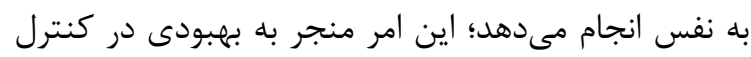

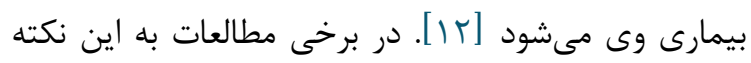

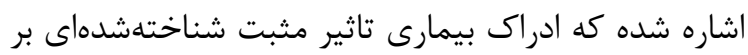

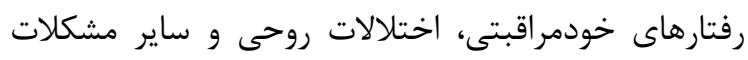

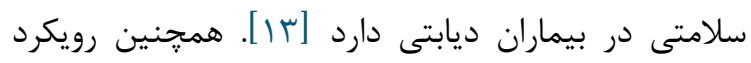

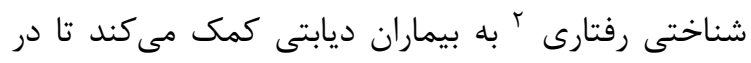

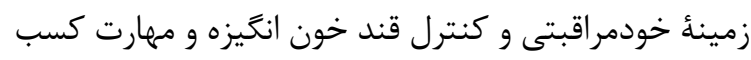

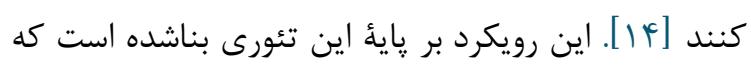

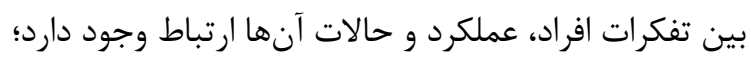

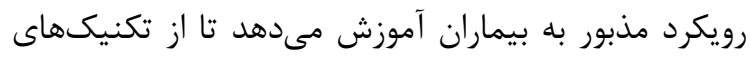

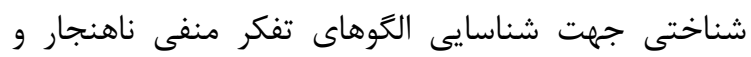

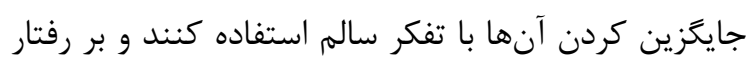

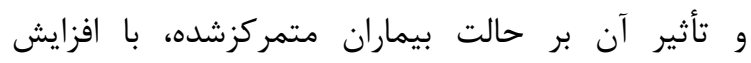

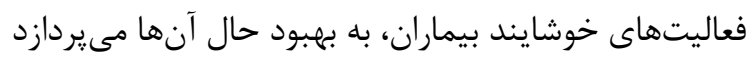

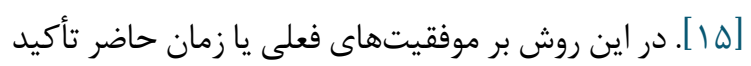

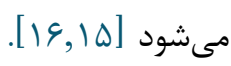

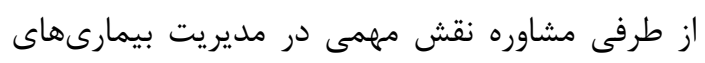

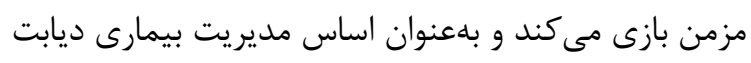

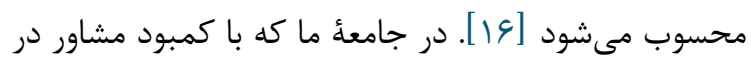

${ }^{1}$ (LMICs) 
اساس مقياس ليكرت از صفر تا V روز نمر ددهى شده و ميزان رعايت

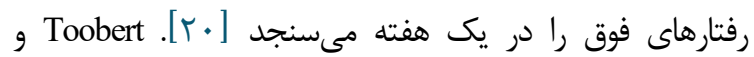

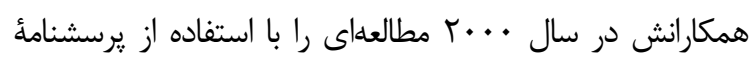

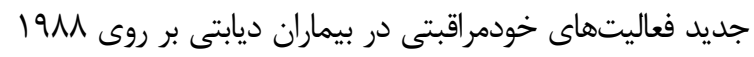

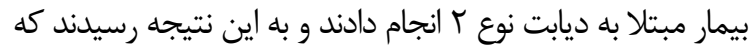
يرسشنامه SDSCA يك خودسنجى كوتامدت و در عين حال

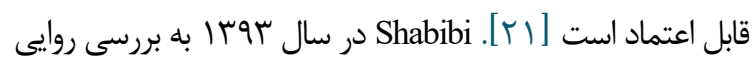

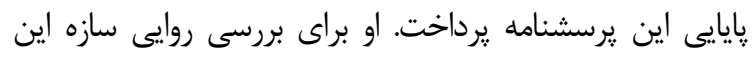

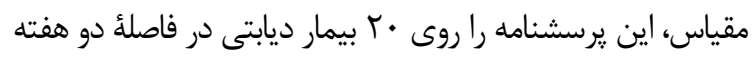

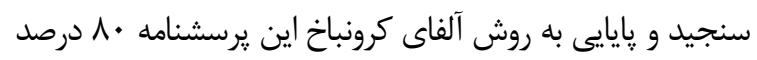

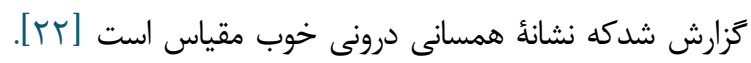

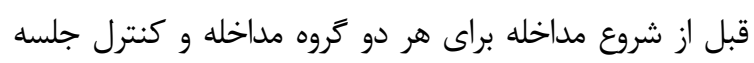

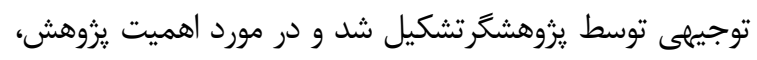

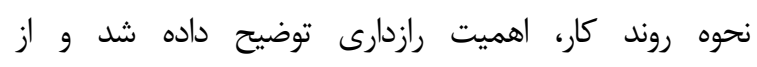

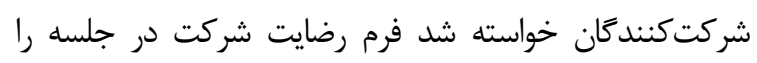

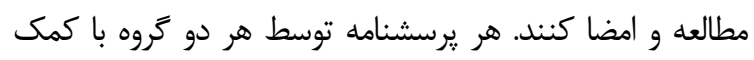

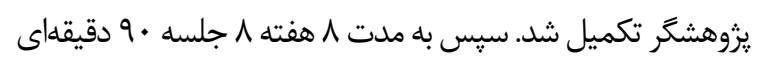

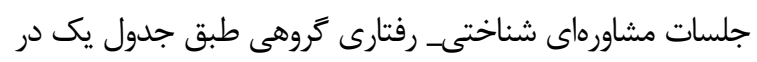

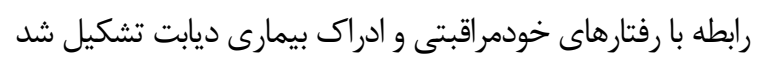

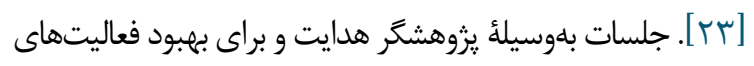

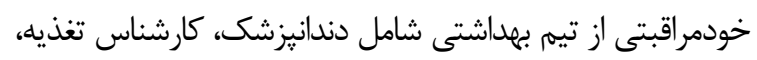

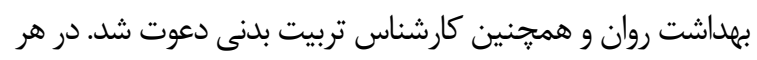

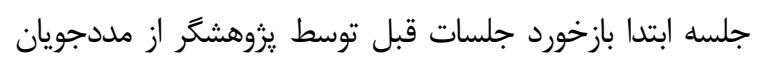

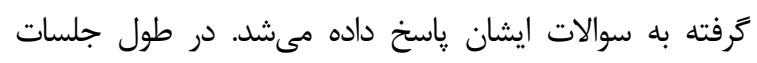
شركت كنندكان فعال بودند و تجارب بيمارى خود رابيان مى كردند.

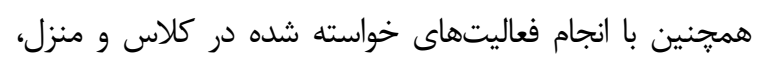

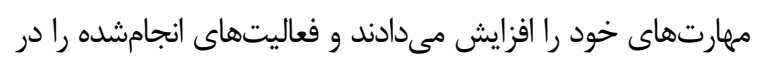

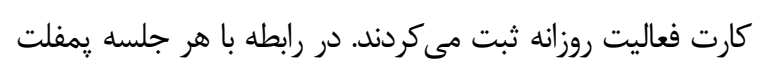

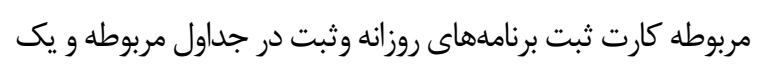

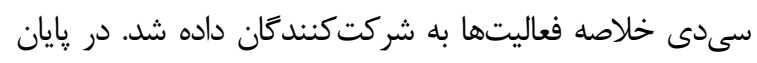

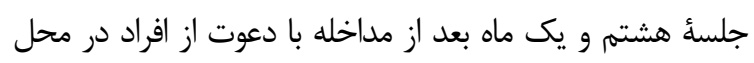

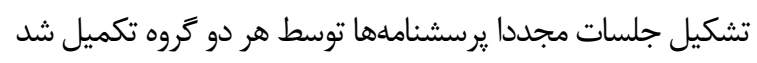

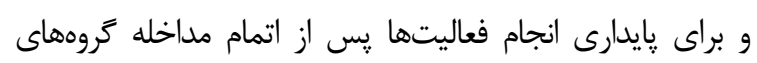

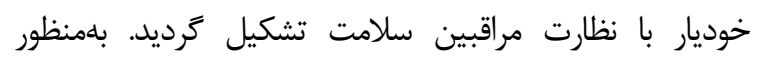

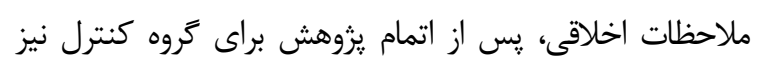

جلسات مشاورهاى بلهورت فشرده در أ جلسه تشكيل شد. دادههاى بهدست آمده در نرمافزار SPSS نسخون (Inc., Chicago, IL., USA
در جلسات مشاورهاى به روش شناختى_رفتارى در رابطه با درمان

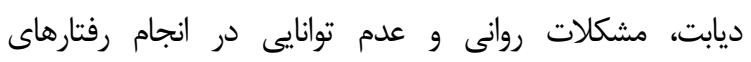

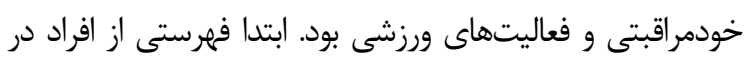

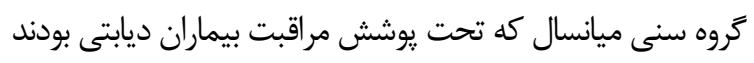

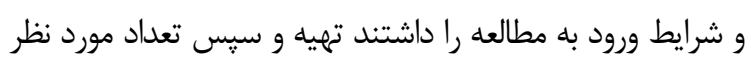

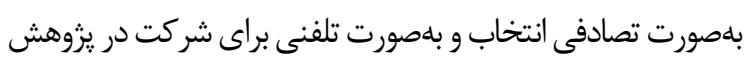

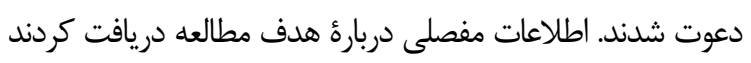

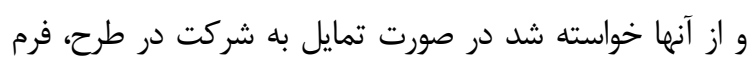

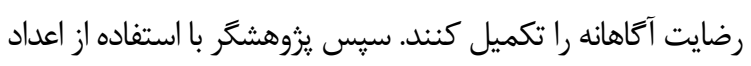

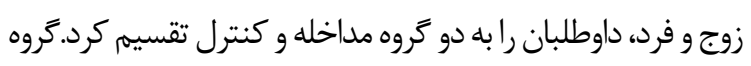

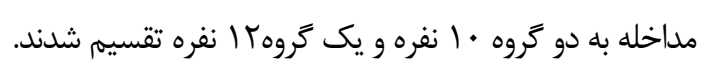

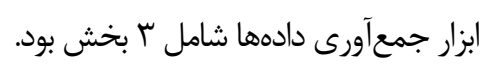

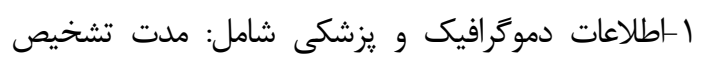

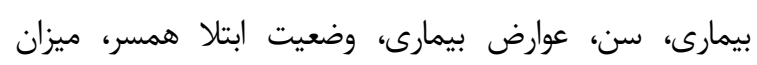
تحصيلات و شغل بود.

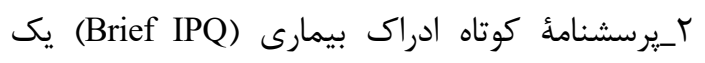

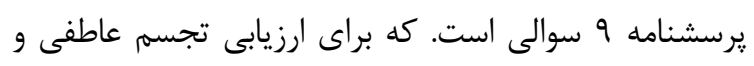

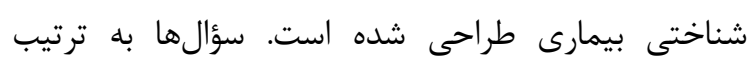

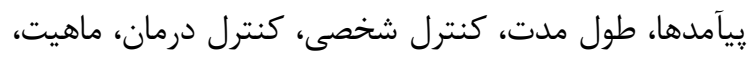

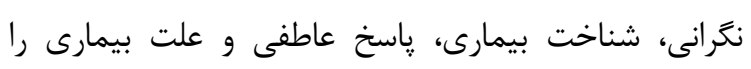

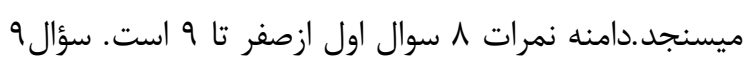

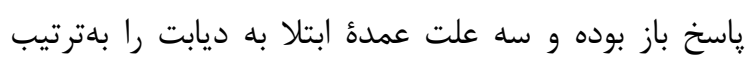

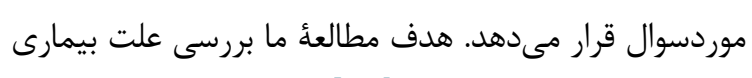

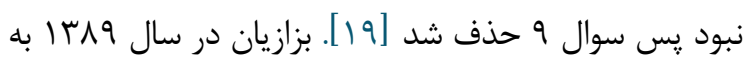

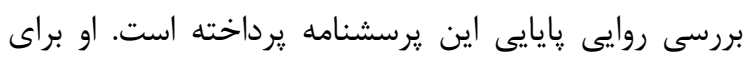
بررسى روايى سازه اين مقياس، تحليل عاملى تائيدى انجام

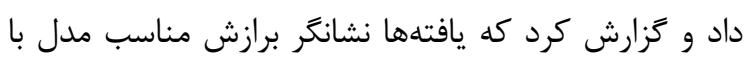

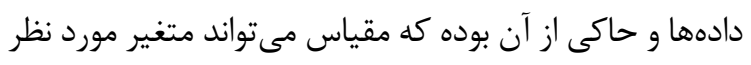

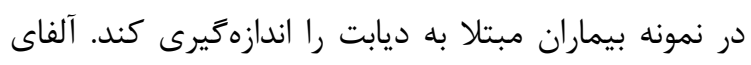

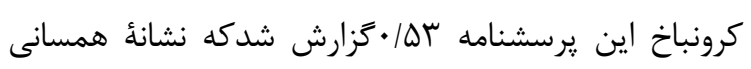

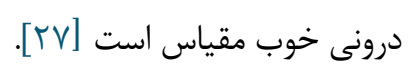
• يرسشنامه سوم: مقياس خلاصه فعاليتهاى خودمراقبتى

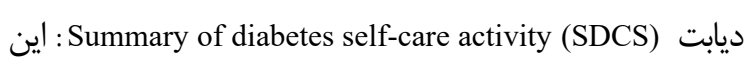
يرسشنامه براى افراد ديابتى جهت سنجش شاخص رفتار

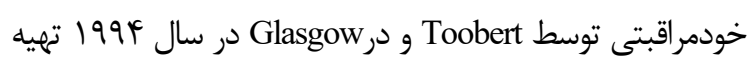
شد. يرسشنامه مذكور ابزار خودگزارشى معتبر · لا سوالى است.

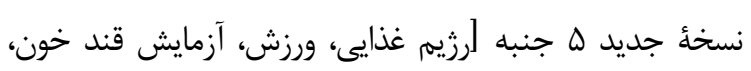

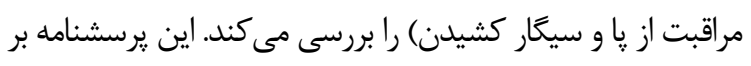




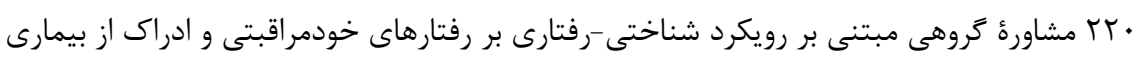

دموكرافيك تفاوت آمارى معنى دارى وجود ندارد (ه •|•P). در كروه مداخله و كنترل .. 1. خانمها خانهدار بودند. همأ همسران

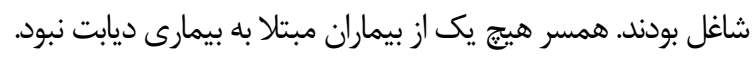

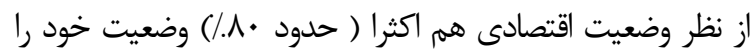
متوسط ارزيابى كرده بودند. مدت تشخيص بيمارى در اكثريت

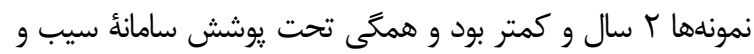
توسط برنامه غربال ترى شناسايى شده بودند.
درصد، ميانكَين و آزمون t مستقل) و تحليلى (ضريب همبستخى

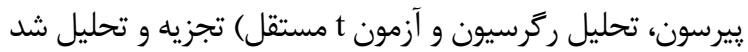
$(P>\cdot / \cdot \Delta)$

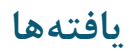

در جدول شماره r، توزيع فراوانى مشخصات دموگرافيك واحدهاى

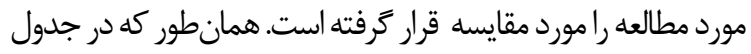

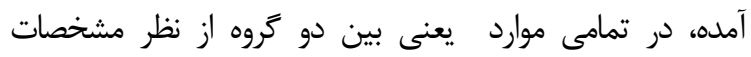

جدول ا. خلاصٔ محتواى جلسات شناختى رفتارى

\section{محتواى جلسات}

\section{جلسات}

معارفه و آشنايى با برنامه و يزوهشكَر، آشنايى با بيمارى ديابت (تعريف اتيولوزى، عوامل خطر، عوارض و درمان ....)

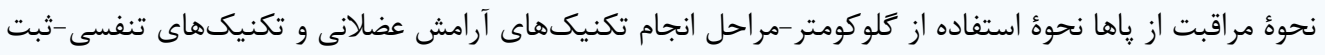
وقايع در جدول فعاليتهاى روزانه -ـارائه پمفلت ديابت

جلسه اول

آشنايى با الكوى شناختى رفتارى مثلث شناختى رفتارى -تكنيكهاى تنفسى و انجام آرميدگى تنفسى توسط

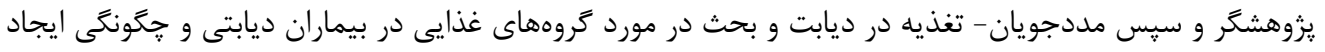

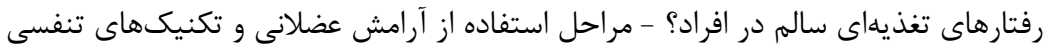

جلسه دوم

آشنايى با ABC تعيين ارتباط بين افكار و احساسات. ورزش و ديابت و توضيح درباره مراحل استفاده از آرامش

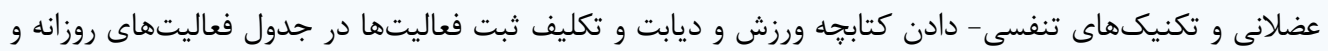

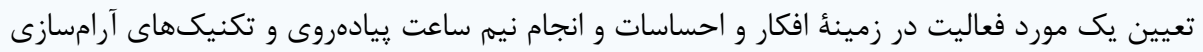
جلسه سوم شناخت ده خطاى شناختى و افكار خودآيند. مشكلات روحى در ديابت و مراحل استفاده از آرامش عضلانى و

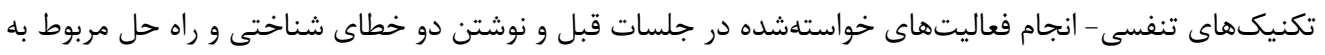
آن-دادن كتابجهُه ديابت و مشكلات روحى تُنى

شناخت تكنيكهاى مقابله با افكار منفى (كامهاى جايكزين افكار منطقى) مراحل استفاده از آرامش عضلانى و

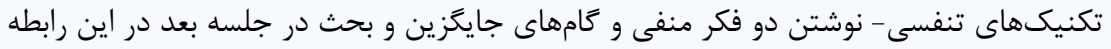

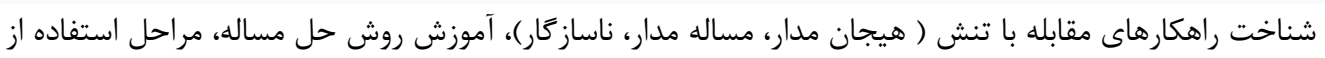

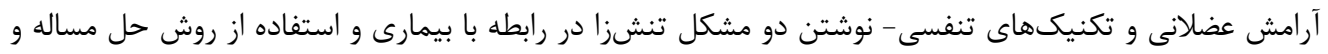

شناخت روش آزمايش افكار بيان افكار منفى و استفاده از افكار جايكزين-مراحل استفاده از آرامش عضلانى و

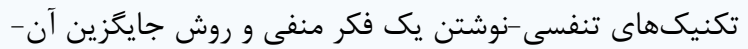

مرور مباحث مطرح شده، دريافت بازخورد اعضا دربارئ مباحث و جمعبندى مطالب، پاسخ به سوالات- تكميل جلسه هشتم يرسشنامه 
جدول r. توزيع فراوانى ويزَى هاى جمعيت شناختى در كروه مداخله و كنترل (ميانغينثانحراف معيار) با تعداد و درصد

\begin{tabular}{|c|c|c|c|c|c|c|}
\hline & \multicolumn{2}{|c|}{ تروه كنترل } & \multicolumn{2}{|c|}{ 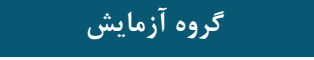 } & \multirow{2}{*}{\multicolumn{2}{|c|}{ مترير }} \\
\hline$P$ & (درصد) & فراوانى & (درصد) & فراوانى & & \\
\hline \multirow{4}{*}{ ( } & 19 & $\Delta$ & $\wedge$ & $\wedge$ & ابتدايى & \multirow{4}{*}{ ت تحصيلات } \\
\hline & r & $1 \cdot$ & 19 & $\Delta$ & متوسطه & \\
\hline & rQ & $\wedge$ & $r V / \Delta$ & ir & دييلم & \\
\hline & $r \wedge$ & 9 & rt & $v$ & دانشعاهى & \\
\hline \multirow{4}{*}{$\cdot / \wedge \Delta \Delta$} & 19 & $\Delta$ & 19 & $\Delta$ & 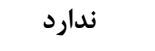 & \multirow{5}{*}{ سابقه بيمارى } \\
\hline & $r V / \Delta$ & ir & щ & 1 . & فشارخون & \\
\hline & r & $1 \cdot$ & rt & v & جربى خون & \\
\hline & rt & v & TQ & $\wedge$ & هردو ل & \\
\hline p-value ${ }^{\#}$ & \multicolumn{2}{|c|}{ ميانغَين||نحر اف معيار } & \multicolumn{2}{|c|}{ ميانكين土|نحر اف معيار } & متغير & \\
\hline .1944 & \multicolumn{2}{|c|}{$r q / 19 \pm r / \wedge \gamma$} & \multicolumn{2}{|c|}{$r \Lambda / \xi \Delta \pm \Psi / \Gamma r$} & \multicolumn{2}{|c|}{ سن (سال)(•r تا 99)سال } \\
\hline$\cdot 1991$ & \multicolumn{2}{|c|}{$1 / \wedge \wedge \pm \cdot / \wedge \Lambda$} & \multicolumn{2}{|c|}{$I / \vee \wedge \pm \cdot / \wedge V$} & \multicolumn{2}{|c|}{$\begin{array}{l}\text { ز زمان تشخيص بيمارى (سال) } \\
\text { *Chi square, \#T test }\end{array}$} \\
\hline
\end{tabular}

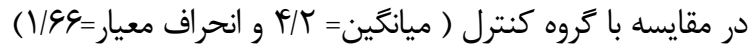

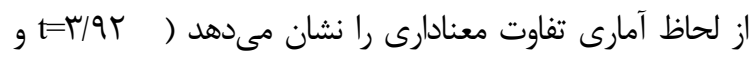

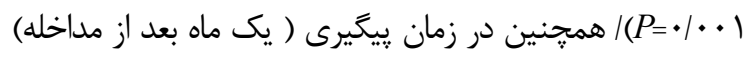
كروه مداخله (ميانگين=F

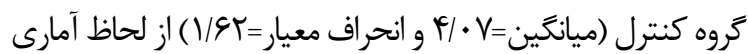

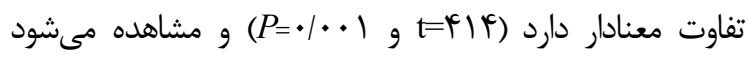
ميانگين نمرةٔ ادراك بيمارى در گروه مداخله در دو زمان نسبت به مارد كروه كنترل مطالعه، روند افزايشى داشته است؛ اين امر نشاندهنده ماندكارى تغييرات در اثر مشاوره است.

\begin{abstract}
وضعيت نرمال بودن دادهها با استفاده از آزمون كولموگرف

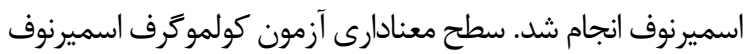
براى متغيرهاى يروهش بيشتر از ه • • است. به عبارت ديخر دادهها از توزيع نرمال برخوردار بودند (ه • • (P). طبق جدول ب، نتايج حاصل از بررسى نشان داد نمرء ادراك از

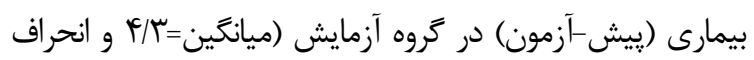

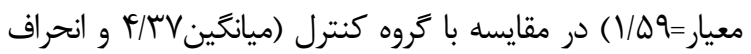
معيار=|(1/1) از لحاظ آمارى تفاوت معنادارى نداشته است مروه

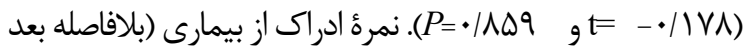
از مداخله) در گروه مداخله (ميانگين=
\end{abstract}

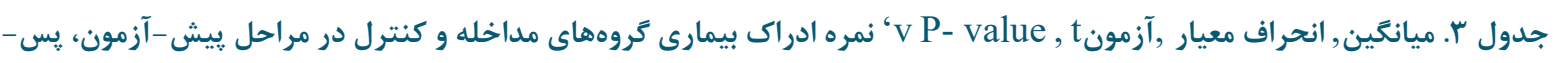

\begin{tabular}{|c|c|c|c|c|c|c|}
\hline$P$ & $\mathbf{t}$ & تفاوت ميانكَين & انحراف معيار & ميانكَن & كروه & آزمون \\
\hline \multirow[t]{2}{*}{$\cdot / 1 \triangle \Delta 9$} & \multirow[t]{2}{*}{$-\cdot / 1 \vee \wedge$} & \multirow[t]{2}{*}{$-\cdot / \cdot V$} & $1 / 09$ & $p / r$ & مداخله & \multirow{2}{*}{ آزيش } \\
\hline & & & $1 / 91$ & $r / r v$ & كنترل & \\
\hline \multirow[t]{2}{*}{$\cdot 1 \cdot \cdot 1$} & \multirow[t]{2}{*}{ r/qr } & \multirow[t]{2}{*}{$r / Q V$} & $\cdot / A V$ & $\Delta / \Delta$ & مداخله & \multirow{2}{*}{ پس آزمون } \\
\hline & & & $1 / 99$ & $f / T$ & كنترل & \\
\hline \multirow[t]{2}{*}{$\cdot 1 \cdot \cdot 1$} & \multirow[t]{2}{*}{ F/Tr } & \multirow[t]{2}{*}{ Q/TT } & $\cdot \mid \Lambda 9$ & $\Delta / F F$ & مداخله & \multirow[t]{2}{*}{ ِيخيرى } \\
\hline & & & $1 / 94$ & $r / \cdot v$ & كنترل & \\
\hline
\end{tabular}


جدول F. ميانكَين، انحراف معيار، آزمون t، P- value نمرؤ رفتارهاى خودمراقبتى كروههاى مداخله و كنترل در مراحل بيش - آزمون،

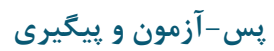

\begin{tabular}{|c|c|c|c|c|c|c|}
\hline P-value & $\mathbf{t}$ & تفاوت ميانكين & انحراف معيار & ميانكَين & كروه & آزمون \\
\hline \multirow[t]{3}{*}{ - $/ \wedge \Delta q$} & \multirow{2}{*}{.$- / . T 4$} & \multirow{2}{*}{$-.1 .9$} & $11 / 10$ & $r V / l$ & مداخله & بيش- \\
\hline & & & $11 / \pi r$ & $r V / T$ & كنترل & آزمون \\
\hline & \multirow[b]{2}{*}{$F / T \Delta$} & \multirow[b]{2}{*}{$1 \cdot / \pi r$} & $N / 1$. & FV/IT & مداخله & \multirow[b]{2}{*}{ يس-آزمون } \\
\hline $.1 . .1$ & & & $11 / 1 \pi$ & rG/VA & كنترل & \\
\hline \multirow[t]{2}{*}{$.1 . .1$} & \multirow{2}{*}{$f / 41$} & \multirow{2}{*}{$1 . \mid 94$} & $N / r)$ & $\mathrm{FV} / .9$ & مداخله & \multirow{2}{*}{ بيكيرى } \\
\hline & & & 1.19 & $r g / 4 q$ & كنترل & \\
\hline
\end{tabular}

بيمارى در كروه مداخله در دو زمان نسبت به كروه كنترل مطالعه روند افزايشى داشته است.

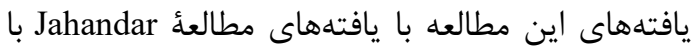

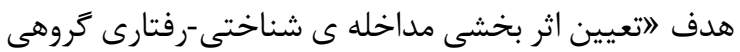

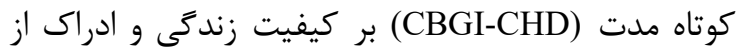
بيمارى، بيماران ديابتى نوع دوه همراستا بود كه نتايجش

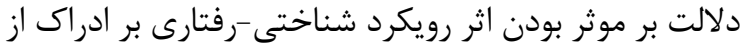
بيمارى بوده است. عاملى كه مطالعه حاضر را از مطالعه Johandar حاضر رفتارهاى خودمراقبتى به جاى كيفيت زندكى بررسى

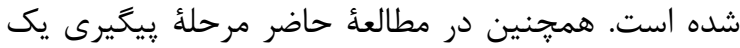

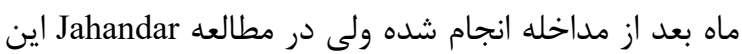

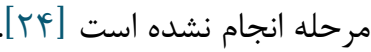
Struss معرض خطر ديابت، بيان كرد اختلافاتى در درك بيمارى

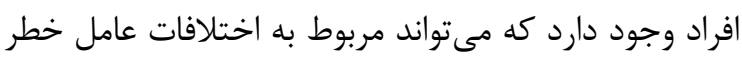
در هر فرد باشد، يس بهتر است كه با توجه به عوامل خطر

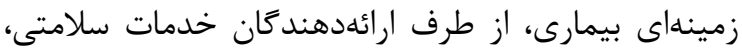
افراد تحت مشاوره و آموزش قرار كيرند. تفاوتهاى مطالعئ

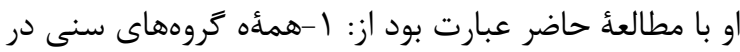
مطالعه شركت داشتند؛ r- فقط در يك مرحله يرسشنامه

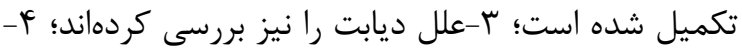

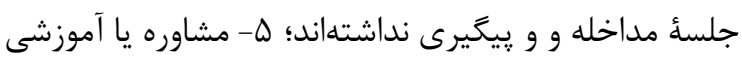
صورت نكرفته است؛ צ- مطالعة گروه كنترل نداشته است .[ra]

در بررسى مقايسٔ ميانكين نمرهٔ تاثير مشاورة گروهى با

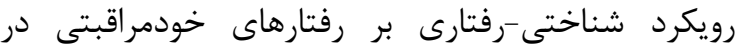

طبق جدول أ، نتايج حاصل از بررسى نشان داد نمرة

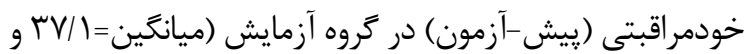

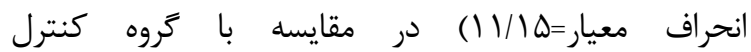

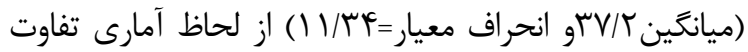
معنادارى نداشته است (r) (t) خودمراقبتى (بلافاصله بعد از مداخله) كروه مداخله

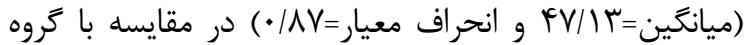
كنترل (ميانكين= آمارى تفاوت معنادارى دارد (T) ( در زمان يیيَيرى ( يك ماه بعد از مداخله) در خروه مداخله (ميانكين=C/F

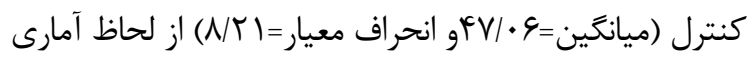

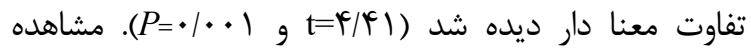
مىشود كه ميانگين نمره خودمراقبتى در گروه مداخله در دو

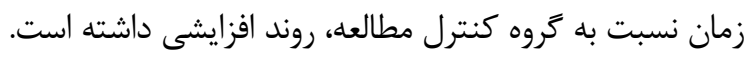
اين مهمم نشاندهندة ماندكارى تغييرات در اثر مشاوره است.

\section{بحث}

مشاوره روانشناختى از عوامل مهم در درك بيمارى و

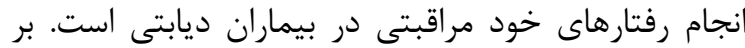

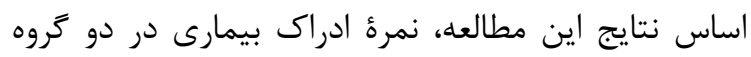

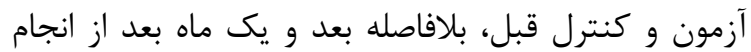
مشاوره شناختى-رفتارى نشان داد در مرحله بيش-آزمون

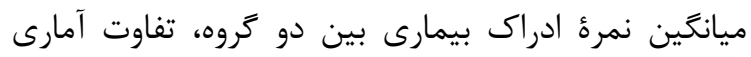

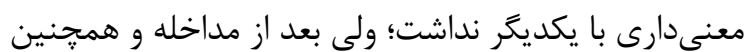
در زمان يِيخيرى ميانگين نمرة ادراك بيمارى بين دو كروه،

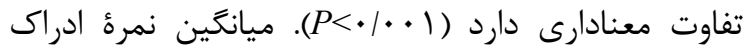


در ميان اكثر بيماران سبب كنترل ضعيفى در ميزان قند

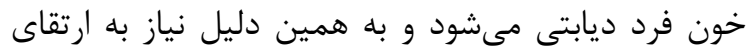

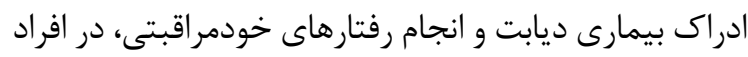

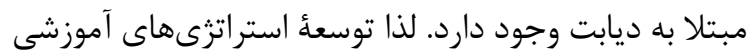
موثر براى بهبود آكاهى از شيوههاى مراقبت از خود توسط

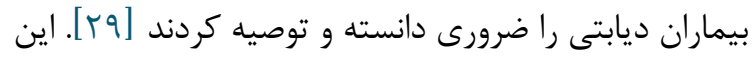

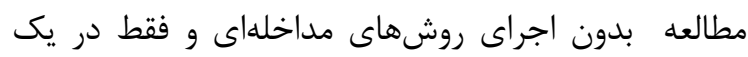

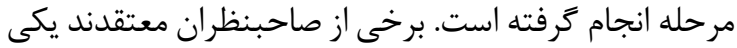

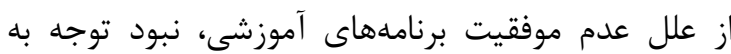

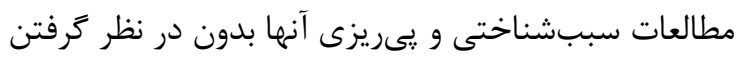

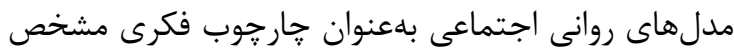

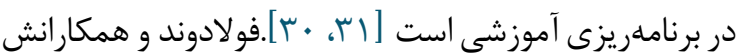

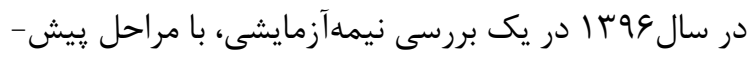

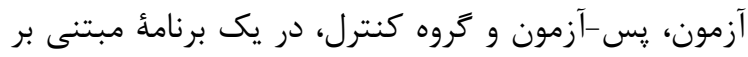

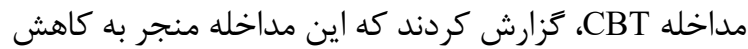

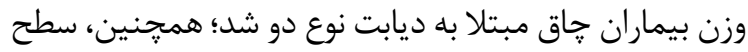

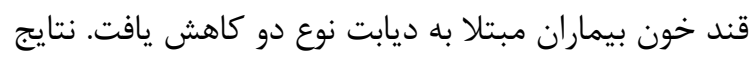
اين مطالعه حاكى از اثربخش بودن روش CBT بر بيماران

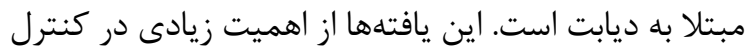

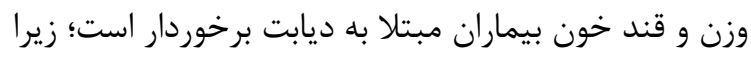

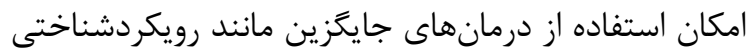

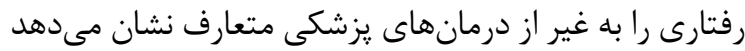

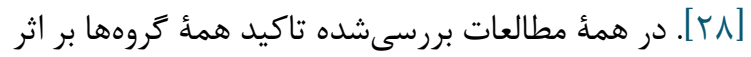
مثبت ادراى بيمارى در رفتارهاى خودمراقبتى بيماران ديابتى نوع r است و بر بالا بردن اطلاعات و آكاهى بيماران در اين رابطه تاكيد شده است. با بررسى نتايج مطالعهُ حاضر بأر

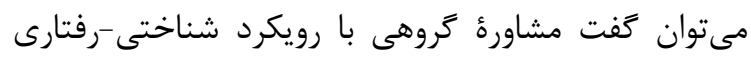
سبب بهبود ادراك از بيمارى و رفتارهاى خودمراقبتى در

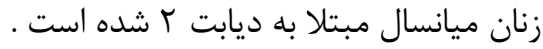

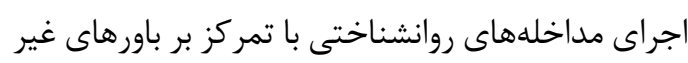
منطقى، آرامسازى عضلانى، آموزش مهارت حلى حل مساله،

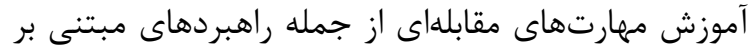

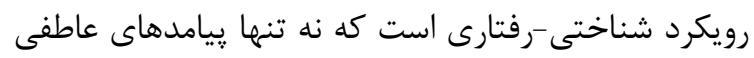

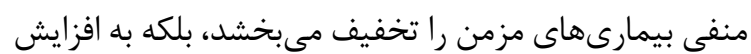

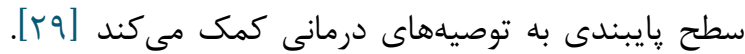

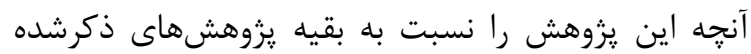

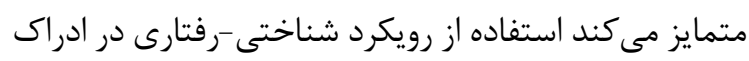

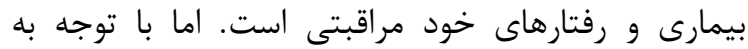

زمانهاى قبل، بلافاصله بعد و يكى ماه بعد از مداخله در دو

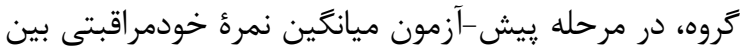

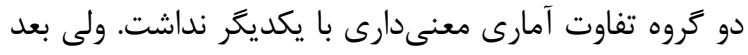

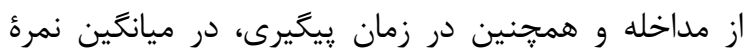
خودمراقبتى بين دو گروه تفاوت معنادارى ديده شد (ميانكَين

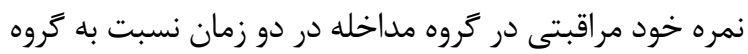

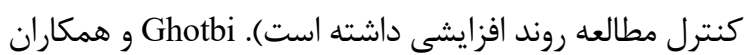

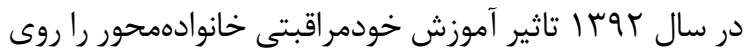

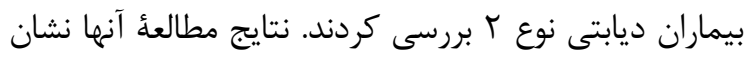

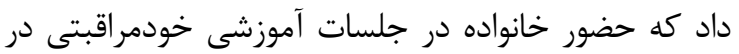

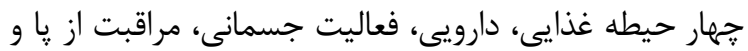

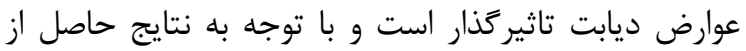

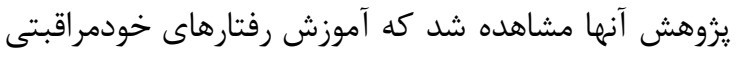

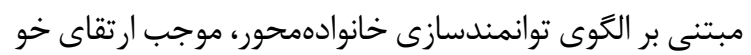

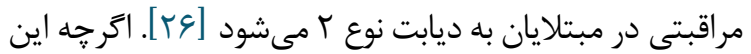

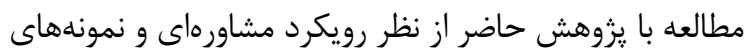

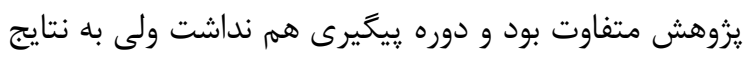
مشابهى رسيده بودند كه بيانكر نياز به انجام مشاوره در افراد

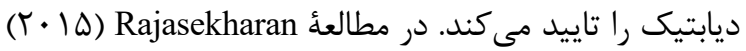

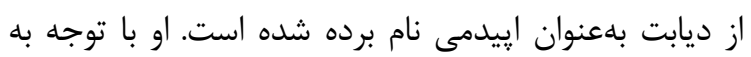
مفهوم جديد مراقبت از خود در بيماران ديابتى ميزان

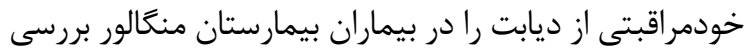

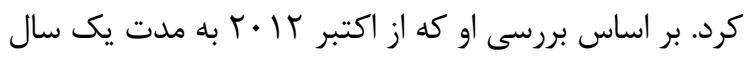

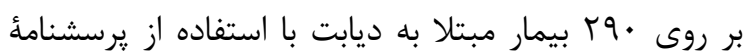
خودمراقبتى ديابت انجام شده بود، روشهاى مراقبت از خود تقريبا در نظارت بر قند خون و تداخل درمان، رضايتبخش

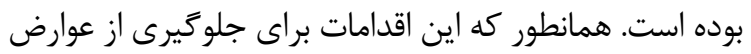
بيمارى و داشتن كيفيت زندگى بهتر ضرورى است، بايد تلاش

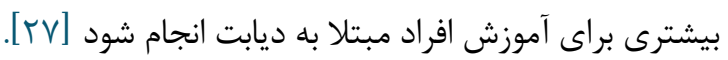

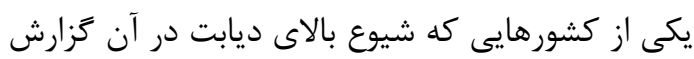

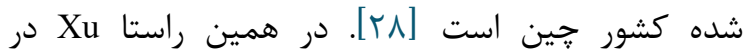
مطالعهاى در سال با.ب با هدف بررسى رفتارهاى

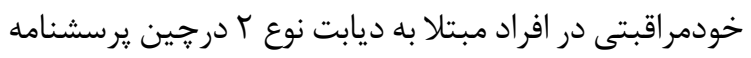
خلاصهشدٔ خودمراقبتى ديابت را در اختيار 199 بيمار قرار داد. يافتههاى اين مطالعه نشان داد كه اكثر بيماران از إنان

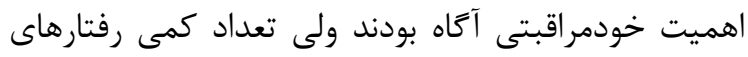

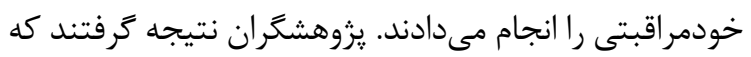
نقص در دانش و شيوههاى مراقبت از خود مربوط به ديابت 


$$
\text { FT مشاورة گروهى مبتنى بر رويكرد شناختى -رفتارى بر رفتارهاى خودمراقبتى و ادراى از بيمارى }
$$

مطالعd حاضر زَزارشى از پايان نامه كارشناسى ارشد با عنوان

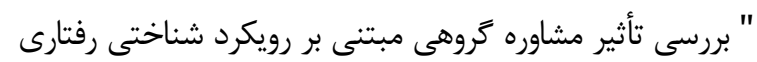

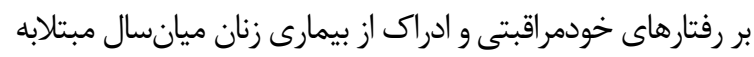

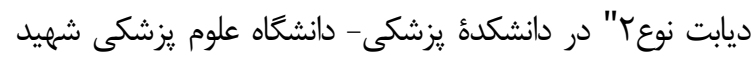
IR.SSU.MEDICINE.RE صدوقى يزد بررسى و باشناسه اخلاق

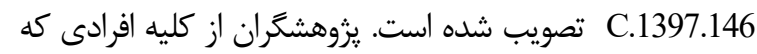
در يزوهش شركت كردند و مسئولين محترم كه در اين زمينه

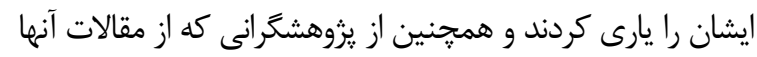
استفاده شده قدردانى و تشكر مى كنند.

$$
\text { تعارض در منافع }
$$

بين نويسندگًان هيجزَّه تعارضى در منافع وجود ندارد
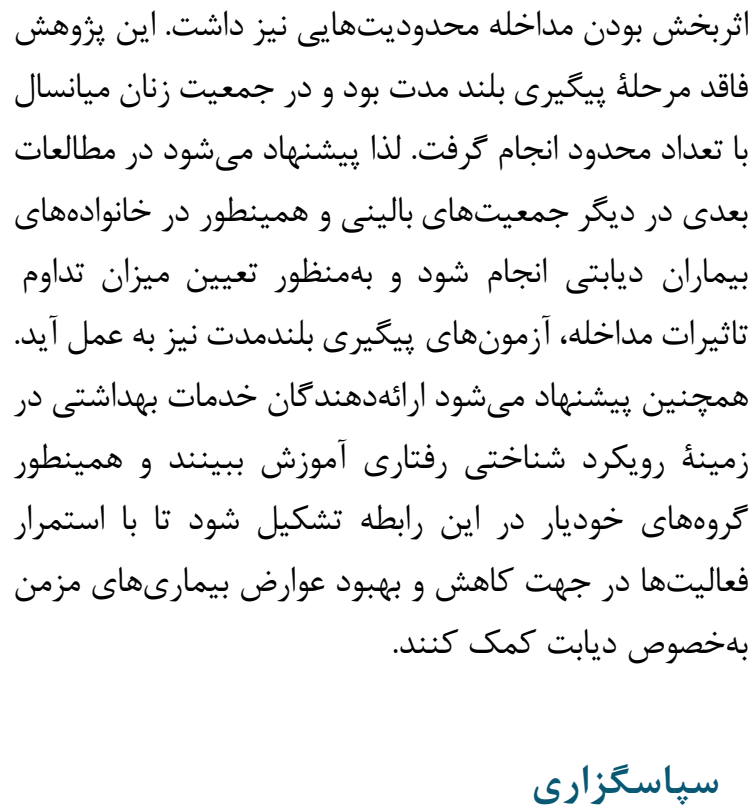

\section{References}

1. Nolte E MM. Caring for people with chronic conditions: a health system perspective, European. Observatory on Health Systems and Policies series New York: Open University Press. 2015.

2. da Silva Marinho MG FA, Vasconcelos Barbosa JM, de Melo Rodrigues H, Freese de Carvalho E, Vieira de Souza W, Pessoa Cesse EA. The impact of an intervention to improve diabetes management in primary healthcare professionals' practices in Brazil. Prim Care Diabetes. 2017(11(6):):538-45. [DOI:10.1016/i.pcd.2017.06.002] [PMID]

3. Sahar Ghashghaie Gn, Rabrert Farnam. The Effectiveness of mindfulness base cognitive therapy on therapy on quality of life in out patients with diabetes. Iranian journal of Diabetes and Metabolism. 2014;.13, No 4.

4. Watkins PJ AS, Howell SL. Diabetes and its management. ed TEt, editor. London: Blackwell;; 2003. [DOI:10.1002/9780470760277]

5. Haghayegh a GN, Neshatdost HT, Kajbaf M, M K. psychometric properties of diabetes management Self-efficacy scale(DMSESS). Iranian journal of endocrinology and metabolism. 2010;12(2):111116. Persian. [DOI:10.1016/j.cmet.2010.07.001] [PMID] [PMCID]

6. Rezasefat Balesbaneh A1 MSN, JafsriAsl M3, Kohmanaee Sh4, Kazemnejad Leili E5, Monfared A6. Correlation between self-care and selfefficacy in adolescents with type 1 diabetes. Comprehensive Nursing and Midwifery, 2014; Year 24, No. 72, Summer 2493 18-24.

7. https://www.who.int/health-topics/diabetes WmcDo. 2019.

8. Adapted from International Diabetes Federation. Brussels, Belgium: International Diabetes Federation, 2011. www.idf.org/diabetesatlas; 2017.

9. Brunner LS SS, Bare BG, Hinkle JL, Cheever KH. Brunner \& Suddarth's textbook of medicalsurgical nursing: Lippincott Williams \& Wilkins; 2010.

10. Rahimi S. relationship between components of lifestyle and incidence of type 2 diabetes among people aged 30 to 60 years in Rasht. Iranian Journal of Diabetes and Metabolism; Vol17, No 2, 2018.

11. SRBL Shrivastava. Role of self-care in management of diabetes mellitus. Journal of Diabetes \& Metabolic Disorders 2013 [DOI:10.1186/2251-6581-12-14] [PMID] [PMCID]

12. Kugbey N OAK, Adulai K. Illness perception, diabetes knowledge and self-care practices among type-2 diabetes patients: a cross-sectional study. BMC Res Notes. 2017;10(1):381. Published 2017 Aug 10. [DOI:10.1186/s13104-017-2707-5] [PMID] [PMCID]

13. L J-H. Cognitive Behavioral Therapy for Diabetic Patients. Korean Diabetes 2015;16(2):141-147 Korean. [DOI:10.4093/jkd.2015.16.2.141]

14. Palizer M. Comparison of Cognitive-Behavioral Therapy and Psychological Training on Blood Glucose Control in Depressed Patients with Type 2 Journal of Qom University of Medical Sciences. 2013.

15. Seyedreza Mazlom MF, Farzaneh Hasanzadeh,Seyedali Kimiaie, Aliakbar Raouf saeb. The Effect of Group Counseling on

$$
\text { مجله مراقبت يُرستارى و مامايى ابنسينا }
$$


Physiological Aspect of Self-care and HbA1C Levelof Patients with Diabetes Type II. Evidence Based Care Journa:. 2015;5(15): 25-36

16. Yahya Eraghi BA-e-FFSG. The Effectiveness of Group Counseling with Cognitive-Behavioral Approach on Reducing Anxiety Symptoms in Schoolchildren. Journal of Educational Sciences. 2011;4(15):13-24.

17. Pahlavanzadeh S, Abbasi S, Alimohammadi N. The effect of group cognitive behavioral therapy on stress, anxiety, and depression of women with multiple sclerosis. Iranian Journal of Nursing and Midwifery Research. 2017;22(4):271-5. [DOI:10.4103/1735-9066.212987] [PMID] [PMCID]

18. Benjamin GTbP, Tayebi Khamene. Metabolic and endocrine diseases womans and mens health. In: 1, editor. Edition2016.

19. Basu S, \& Poole, J. The Brief Illness Perception Questionnaire. Occupational medicine (Oxford, England), 2016;66(5), 419-420. [DOI:10.1093/occmed/kqv203] [PMID] [PMCID]

20. Samadzadeh N PH, Babapour Khairuddin 1. The Effectiveness of Cognitive-Behavioral Therapy on Social Anxiety Adaptation with Depression and Disease Symptoms in Type 2 Diabetes. Quarterly Journal of Clinical Psychology Studies, No 17, Fifth Year, Winter 33. 2015.

21. Toobert DJ, Hampson, S.E., Glasgow, R.E. The summary of diabetes self-care activities measure: results from 7 studies and a revised scale. Diabetes care 2000;7(23):943-50. [DOI:10.2337/diacare. 23.7.943] [PMID]

22. ShabibiP MM, Abedzadehzavareh M, Sayehmiri K. The Status of Self-Care Behaviors in Patients with Type 2 Diabetes in the City of Ilam in 2014. Scientific Journal of Ilam University of Medical Sciences. 2015;24(2):63-71

[DOI:10.18869/acadpub.sjimu.24.2.63]

23. Branch R WR. Cognitive Behavioral Therapy. 4, editor. london: WILLY; 2019.

24. JahandarM B, Mohammad taghi BadelehM, S. The effectiveness of a short cognittive behavioral group intervention on quality of life and ilness perception in patients with type 2 diabetes disease. Iranian journal of Diabetes and Metabolism. 2016;15(6)

25. Strauss SM RM, Kaur N. Illness perceptions among adults at risk for diabetes. Diabetes Educ. 2015;41(2):195-202. [DOI:10.1177/0145721715569003] [ [PMID] [PMCID]

26. Ghotbi. T SBM, Dalvand., Arsalani, Farzi M. The effect of education of self care behaviors based on family-centered empowerment model in type II diabetes. Journal of Nursing and Midwifery Faculty. 2014;23(83):43-6.

27. Bazzazian S, Besharat M, Bahrami Ehsan H, Rajab A. The Moderating Role of Coping Strategies in Relationship Between Illness
Perception, Quality of Life and HbAlc in Patients with Type I Diabetes. Iranian Journal of Endocrinology and Metabolism. 2010; 12 (3) :213-221 URL: http://ijem.sbmu.ac.ir/article-1-838-fa.html

28.

29. FouladvandM , L.K.F., VaziriS , Ahadi H, The Effectiveness of Cognitive-Behavioral Group Therapy on Weight Loss and Blood Glucose Level in Women with Type rDiabetSun Yzlmm. Experimental and Therapeutic Medicine china. 2013;1137-42 p.

30. Vazini H BM. Predicting Factors Related to Selfcare Behaviors among Type 2 Diabetic Patients based on Health Belief Model. Journal of Torbat Heydarieh University of Medical Sciences.2014,1(4):16-25.

31. Simbar M RTF, Hashemi Z. Sexual-Reproductive Health Belief Model of Iranian South Medical Journal. 2004;7(1):70-8.

32. FouladvandM LKF, VaziriS , Ahadi H. The Effectiveness of Cognitive-Behavioral Group Therapy on Weight Loss and Blood Glucose Level in Women with Type 2 Diabetes - Journal of Research in Behavioral Sciences 2019;1(4):403 39.

33. Najmi B AH, Delavar A, Hashemipoor M. The Effectiveness of Multidimentional Psychological Treatment in Enhancing the Adherence to Medical Treatment in Adolescents with Type 1 Diabetes. Journal of Research in Behavioural Sciences 2007; 5(2): 127-136.

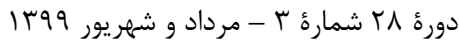

